THE $11^{\text {TH }}$ EDITION OF

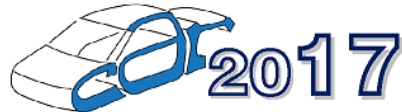

The International Congress of Automotive and Transport Engineering

MOBILITY ENGINEERING AND ENVIRONMENT

November 8-10, 2017

\title{
Mathematical method for studying passenger flows in Craiova Municipality public transport system
}

\author{
Lucian MATEI, Mihaela RACILA, Alexandru OPRICA, Neagoe DUMITRU, \\ Ilie DUMITRU*, Laurentiu RACILA \\ University of Craiova, Faculty of Mechanical Engineering, Calea Bucuresti str, no. \\ 107, 200512, Craiova, Dolj, Romania
}

*Corresponding author e-mail: dumitru_ilie@yahoo.com

Article history

Received 10.06.2017

Accepted 23.09.2017

DOI https://doi.org/10.26825/bup.ar.2017.001

\begin{abstract}
Public transport in general contributes to cleaner air and better quality of life in cities and reduces greenhouse gas (GHG) emissions. For this is important that the public transport system to be very well analysed in regards to displacement of daily trips. The aim of the paper is to get a new introspection into the measurements and mathematical equations that were used in calculating the displacement volume of trips in Craiova Municipality public transport system. The calculation method was developed in order to compensate the short time that was allocated to the real data collection from the public transport system and to better understand the random phenomena related to the variation in the volume of daily trip movements of passenger in Craiova public transport system.
\end{abstract}

\section{Introduction}

Monitoring of passenger displacement trip volume patterns and trends in urban areas is an important element in assessing issues of what type of optimization methods to use in the public transport with regards to sustainable development of cities and their surroundings areas $[1,2]$. Public transport of passengers in Craiova is provided by the Craiova Autonomous Transport Administration (RAT Craiova), which has at the level of the city two types of transport networks:

- Tramway network

$\circ$ Two-way line from West to East

- Bus network
○ Radial
- Linear 


\section{- Concentric}

This paper describes the results of a new calculation method that creates comparable indicators on the trip displacement volumes by the public transport system with a minimum length of a survey. The impacts of increasing frequencies or adding new lines and stops can easily be measured based on the results of the calculation [3].

\section{Craiova public transport network}

The public transport activity of RAT Craiova is characterized by the many technical and economic indicators as well from the figures bellow:

Table 1. Technical and Economic Indicators October 2016

\begin{tabular}{|l|c|c|c|}
\cline { 2 - 4 } \multicolumn{1}{c|}{} & Trams & Buses & Minibuses \\
\hline The length of the transport network [km] & 35 & \multicolumn{2}{|c|}{120} \\
\hline Fleet inventory [units] & 25 & \multicolumn{2}{|c|}{185} \\
\hline The circulating motor vehicle park [units] & 25 & 122 & 7 \\
\hline Coefficient of use & $15 \%$ & \multicolumn{2}{|c|}{$85 \%$} \\
\hline Annual average run [veh*km] & $56.548,1$ & $415.875,1$ \\
\hline Number of passengers transported per month & $363.325,14$ & 2.097 .509 \\
\hline
\end{tabular}

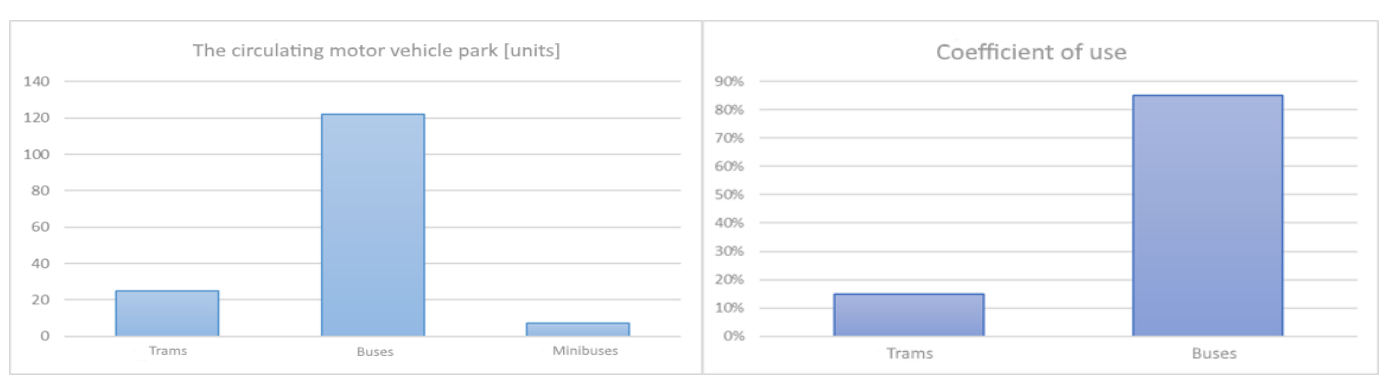

Figure 1. Technical fleet indicators of RAT Craiova.

\subsection{Principal lines of the public transport system}

There are two main public transport networks in the Municipality of Craiova: buses network and tram network.

Tramway public transport network is developing in the East-West direction and consists of the route no. 100, which serves most of the city, between the Calea Severin gas station and the Electroputere passage, with the technical characteristics that can be seen in the figures bellow.

One the best routes from the busses network was developed for better service of industrial platforms and important commercial areas in Craiova. The public transport lines are made by two routes with inelar character no. E1T and E1R connecting one of the biggest neighbourhoods and industrial platforms as can be seen from the figures bellow.
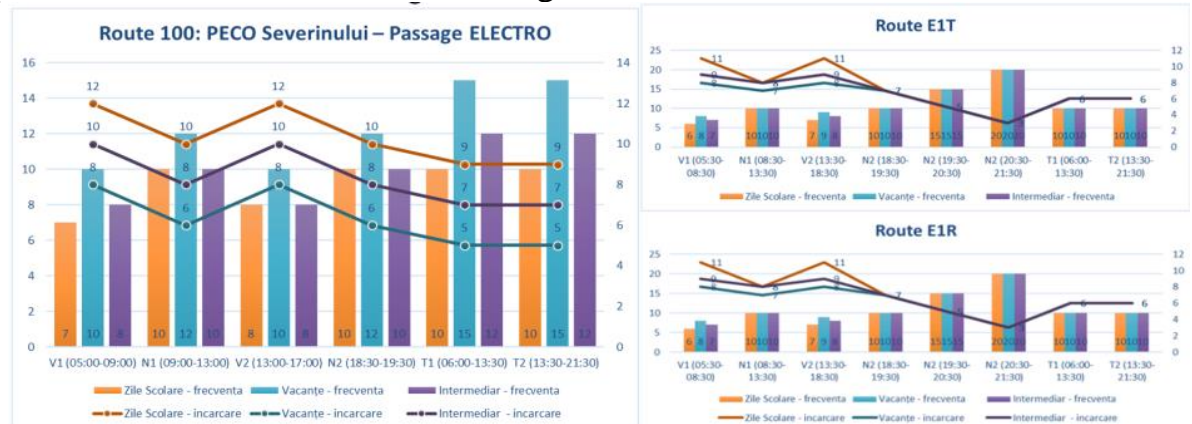

Figure 2. Technical characteristics of public transport route 100, E1T and E1R.

For reasons of the urbanistic structure of Craiova, most of the public passenger transport is carried out on a radial-concentric structure. At the same time, due to the central area located in the middle of the city, the routes are designed so that the service of the central commercial-economic space is 
maximal. The take advantage of the urbanistic structure of Craiova city, there are 15 routes with different technical characters. The most important and most common routes are presented below in terms of load and frequency.

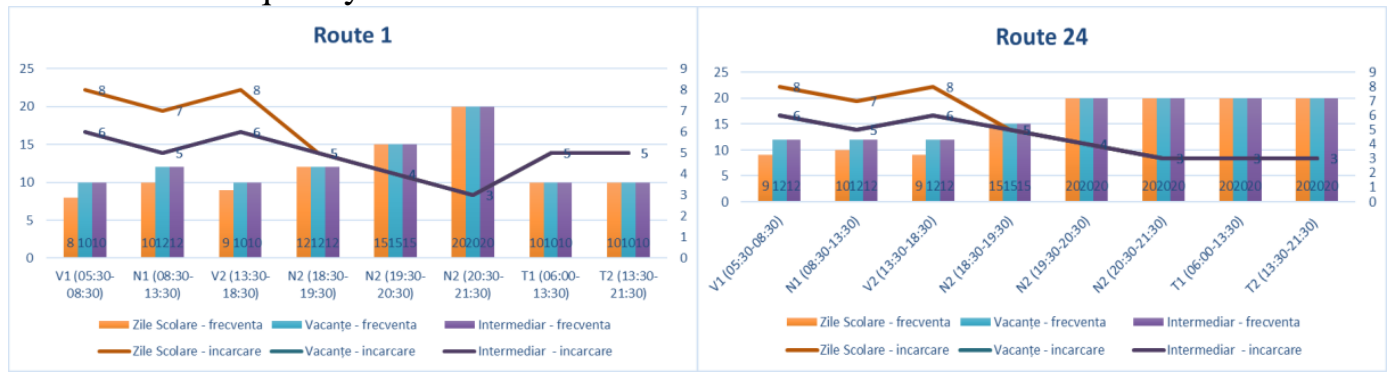

Figure 3. Load and frequency of public transport route 1 and 24.

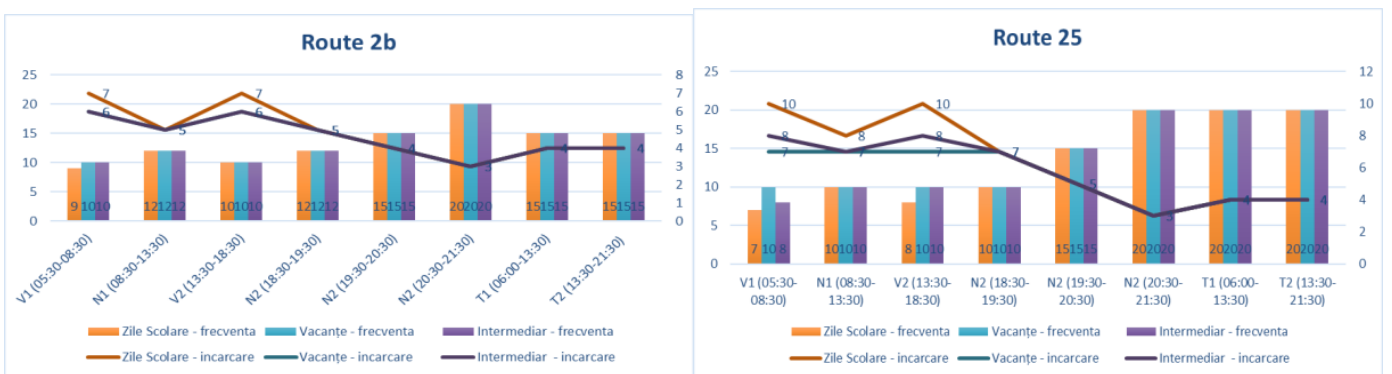

Figure 4. Load and frequency of public transport route $2 \mathrm{~b}$ and 25 .

\section{Public transport trips computation}

In order to maintain the deadline for the project and to make an evaluation of the trips and to calculate the economic status of the transport system in Craiova we needed two main things:

- Measure the passenger trips in different days [4]

- Create a function based on the measurements and generate the rest of the data $[3,4,5]$

\subsection{Passengers trip counting results}

The passenger trip counting was done by human counters in every public transport line. The counters were placed on each door of the public transport vehicle. The human counter was chosen at the expense of mode advanced technical solution mainly because of the following reasons:

- The ascending and descending is done on every door of the vehicle.

- The ascending and descending is done in the same time

- The passengers can stay next to the exit doors

The passenger trips were measured on Monday, Thursday, Sunday and Saturday. The measurement from Monday was the base one, and the other ones were the measurements that we needed to calibrate and validate the equation [6].

Table 2. Passenger trips measurements from Monday

\begin{tabular}{|c|c|c|c|c|c|}
\cline { 2 - 5 } \multicolumn{1}{c|}{$5: 30-6: 30$} & $6: 30-7: 30$ & $7: 30-8: 30$ & $8: 30-9: 30$ & \multirow{4}{*}{} \\
\hline \multirow{4}{*}{ Monday } & 398 & 1921 & 1836 & 1307 \\
\cline { 2 - 5 } & $9: 30-10: 30$ & $10: 30-11: 30$ & $11: 30-12: 30$ & $12: 30-13: 30$ \\
\cline { 2 - 5 } & 831 & 426 & 374 & 619 \\
\cline { 2 - 5 } & $13: 30-14: 30$ & $14: 30-15: 30$ & $15: 30-16: 30$ & $16: 30-17: 30$ \\
\cline { 2 - 5 } & 600 & 915 & 1703 & 1322 \\
\cline { 2 - 5 } & $17: 30-18: 30$ & $18: 30-19: 30$ & $19: 30-20: 30$ & $20: 30-21: 30$ \\
\cline { 2 - 5 } & 857 & 338 & 235 & 70 \\
\hline
\end{tabular}



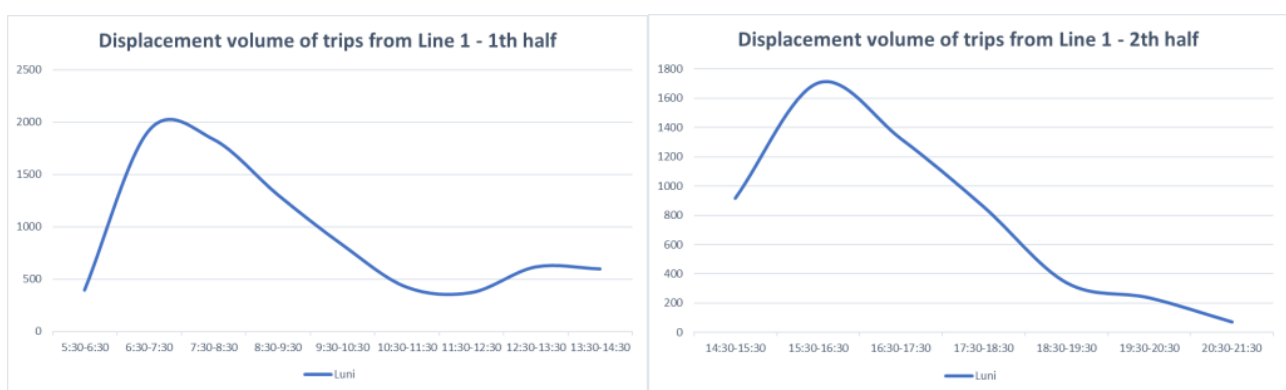

Figure 5. Displacement volume of trips splitted in half.

Based on the values presented in the table above we splitted the measures in two main intervals from 5:30 to $14: 30$ and from 14:30 to $21: 30$. Using dedicated mathematical software's we established a general $4^{\text {th }}$ degree polynomic function that can be used to generate the passenger trips for the rest of the week (from Monday to Friday) as can be seen in the equations bellow [7, 8].

$$
\begin{aligned}
& f(x)=-9.6512 \cdot x^{4}+225.75 \cdot x^{3}-1799.5 \cdot x^{2}+5388.4 \cdot x-3384.8 \\
& f(x)=-14.428 \cdot x^{4}+275.49 \cdot x^{3}-1824.1 \cdot x^{2}+4520.2 \cdot x-2037.7
\end{aligned}
$$

The next step was to establish a $5^{\text {th }}$ degree polynomic function based on the Saturday so we can calculate Sunday passenger trips [7, 8]. This was done by dividing intro three the displacement of the volume trips like in the figures bellow.
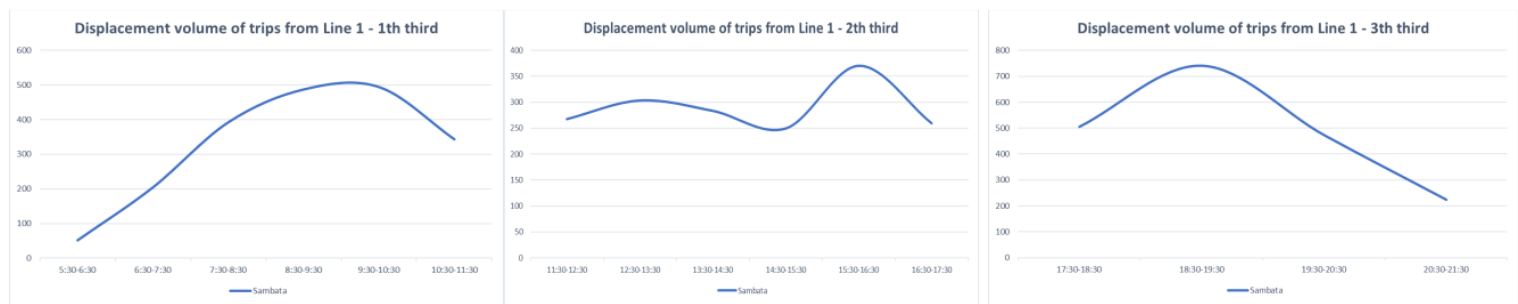

Figure 6. Displacement volume of trips on Saturday splitted in third.

Using the same mathematical software's like above we established the following polynomial equation.

$$
\begin{gathered}
f_{1}(x)=-1.7333 \cdot x^{5}+31.542 \cdot x^{4}-224.08 \cdot x^{3}+729.46 \cdot x^{2}-886.18 \cdot x+403 \\
f_{2}(x)=-5.6917 \cdot x^{5}+90.667 \cdot x^{4}-529.71 \cdot x^{3}+1395.8 \cdot x^{2}-1627.1 \cdot x+943 \\
f_{3}(x)=87 \cdot x^{3}-774 \cdot x^{2}+1949 \cdot x-757
\end{gathered}
$$

Based on the above equations we determined that the polynomic function that will generate the next days of the week will be the following relations:

$$
\begin{aligned}
& f_{1}(x)=k_{5} \cdot x^{5}+k_{4} \cdot x^{4}+k_{3} \cdot x^{3}+k_{2} \cdot x^{2}+k_{1} \cdot x+k_{0} \\
& f_{2}(x)=u_{5} \cdot x^{5}+u_{4} \cdot x^{4}+u_{3} \cdot x^{3}+u_{2} \cdot x^{2}+u_{1} \cdot x+u_{0} \\
& f_{3}(x)=r_{5} \cdot x^{5}+r_{4} \cdot x^{4}+r_{3} \cdot x^{3}+r_{2} \cdot x^{2}+r_{1} \cdot x+r_{0}
\end{aligned}
$$

The coefficients $k, u$ and $r$ will be replaced by values that we going that will be used to calculate the passenger trips on the next days of the week $[9,10]$. 
3.2. Coefficients computation for the whole week

Based on the polynomial functions from above and using different mathematical algorithms we managed to filtered coefficients between a minimum and a maximum value [11].

Table 3. Minimum and maximum values of the coefficients used to calculate the passenger trips in the weekdays

\begin{tabular}{|l|l|l|}
\hline & Minim & Maxim \\
\hline $\mathbf{k}_{\mathbf{5}}$ & 0 & 0 \\
\hline $\mathbf{k}_{\mathbf{4}}$ & -10 & -7 \\
\hline $\mathbf{k}_{\mathbf{3}}$ & 178 & 226 \\
\hline $\mathbf{k}_{\mathbf{2}}$ & -1800 & -1442 \\
\hline $\mathbf{k}_{\mathbf{1}}$ & 4391 & 5389 \\
\hline $\mathbf{k}_{\mathbf{0}}$ & -3429 & -2791 \\
\hline
\end{tabular}

\begin{tabular}{|l|l|l|}
\hline & Minim & Maxim \\
\hline $\mathbf{u}_{\mathbf{5}}$ & 0 & 0 \\
\hline $\mathbf{u}_{\mathbf{4}}$ & -15 & -6 \\
\hline $\mathbf{u}_{\mathbf{3}}$ & 140 & 276 \\
\hline $\mathbf{u}_{\mathbf{2}}$ & -1825 & -1010 \\
\hline $\mathbf{u}_{\mathbf{1}}$ & 2665 & 4521 \\
\hline $\mathbf{u}_{\mathbf{0}}$ & -2038 & -914 \\
\hline
\end{tabular}

Table 4. Minimum and maximum values of the coefficients used to calculate the passenger trips in the weekends

\begin{tabular}{|l|l|l|}
\hline & Minim & Maxim \\
\hline $\mathbf{k}_{\mathbf{5}}$ & -2 & 0 \\
\hline $\mathbf{k}_{\mathbf{4}}$ & 18 & 32 \\
\hline $\mathbf{k}_{\mathbf{3}}$ & -225 & -139 \\
\hline $\mathbf{k}_{\mathbf{2}}$ & 493 & 730 \\
\hline $\mathbf{k}_{\mathbf{1}}$ & -887 & -658 \\
\hline $\mathbf{k}_{\mathbf{0}}$ & 322 & 403 \\
\hline
\end{tabular}

\begin{tabular}{|l|l|l|}
\hline & Minim & Maxim \\
\hline $\mathbf{u}_{\mathbf{5}}$ & -6 & 2 \\
\hline $\mathbf{u}_{\mathbf{4}}$ & -26 & 91 \\
\hline $\mathbf{u}_{\mathbf{3}}$ & -530 & 215 \\
\hline $\mathbf{u}_{\mathbf{2}}$ & -809 & 1396 \\
\hline $\mathbf{u}_{\mathbf{1}}$ & -1628 & 1305 \\
\hline $\mathbf{u}_{\mathbf{0}}$ & -463 & 943 \\
\hline
\end{tabular}

\begin{tabular}{|l|l|l|}
\hline & Minim & Maxim \\
\hline $\mathbf{r}_{\mathbf{5}}$ & 0 & 0 \\
\hline $\mathbf{r}_{\mathbf{4}}$ & 0 & 0 \\
\hline $\mathbf{r}_{\mathbf{3}}$ & -20 & 87 \\
\hline $\mathbf{r}_{\mathbf{2}}$ & -774 & 31 \\
\hline $\mathbf{r}_{\mathbf{1}}$ & 163 & 1949 \\
\hline $\mathbf{r}_{\mathbf{0}}$ & -757 & 222 \\
\hline
\end{tabular}

3.3. Polynomial equations used to generate the passenger trips for a whole week

The minimum and maximum values that are presented in the above tables are not enough to generate the values for the passenger trips. Using these limits, we managed through different software's and algorithms to find all the fixed values for the coefficients in all days of the week [12]. The next equations will present the polynomial functions for all days of the week and all splits.

$$
\begin{gathered}
f(x)=-9.6512 \cdot x^{4}+225.75 \cdot x^{3}-1799.5 \cdot x^{2}+5388.4 \cdot x-3384.8 \\
f(x)=-9.9272 \cdot x^{4}+225.07 \cdot x^{3}-1735.7 \cdot x^{2}+5048.5 \cdot x-3113.8 \\
f(x)=-7.5023 \cdot x^{4}+178.24 \cdot x^{3}-1442.5 \cdot x^{2}+4391.2 \cdot x-2791.1 \\
f(x)=-8.6597 \cdot x^{4}+207.17 \cdot x^{3}-1689.7 \cdot x^{2}+5185.8 \cdot x-428.4 \\
f(x)=-9.2389 \cdot x^{4}+214.72 \cdot x^{3}-1703.4 \cdot x^{2}+5099.6 \cdot x-3229.2 \\
f(x)=-1.7333 \cdot x^{5}+31.542 \cdot x^{4}-224.08 \cdot x^{3}+729.46 \cdot x^{2}-886.18 \cdot x+403 \\
f(x)=-0.9083 \cdot x^{5}+18 \cdot x^{4}-139.29 \cdot x^{3}+493.5 \cdot x^{2}-658.3 \cdot x+322 \\
f(x)=-14.428 \cdot x^{4}+275.49 \cdot x^{3}-1824.1 \cdot x^{2}+4520.2 \cdot x-2037.7 \\
f(x)=-11.03 \cdot x^{4}+218.26 \cdot x^{3}-1490.3 \cdot x^{2}+3772.4 \cdot x-1663.7 \\
f(x)=-11.727 \cdot x^{4}+227.03 \cdot x^{3}-1529.3 \cdot x^{2}+3869.6 \cdot x-1805.6 \\
f(x)=-9.1591 \cdot x^{4}+183.93 \cdot x^{3}-1278.2 \cdot x^{2}+3297.2 \cdot x-1491.7 \\
f(x)=-6.803 \cdot x^{4}+140.52 \cdot x^{3}-1010.7 \cdot x^{2}+2665.8 \cdot x-914.29 \\
f(x)=-5.6917 \cdot x^{5}+90.667 \cdot x^{4}-529.71 \cdot x^{3}+1395.8 \cdot x^{2}-1627.1 \cdot x+943 \\
f(x)=1.0667 \cdot x^{5}-25.292 \cdot x^{4}+214.92 \cdot x^{3}-808.71 \cdot x^{2}+1305 \cdot x-463 \\
f(x)=87 \cdot x^{3}-774 \cdot x^{2}+1949 \cdot x-757 \\
f(x)=-19.167 \cdot x^{3}+30.5 \cdot x^{2}-162.67 \cdot x+222
\end{gathered}
$$




\subsection{Polynomial equation validation and error}

The real data set for the passenger trips is available for Monday, Thursday, Sunday and Saturday. Based on these values we managed to obtain the following comparison tables.

Table 5. Calculated and measured results for first half of the weekdays

\begin{tabular}{|c|c|c|c|c|c|c|c|c|}
\hline \multicolumn{10}{|c|}{ Calculated results } \\
\hline $5: 30-$ & $6: 30-$ & $7: 30-$ & $8: 30-$ & $9: 30-$ & $10: 30-$ & $11: 30-$ & $12: 30-$ & $\begin{array}{c}13: 30- \\
14: 30\end{array}$ \\
\hline $6: 30$ & $7: 30$ & $8: 30$ & $9: 30$ & $10: 30$ & $11: 30$ & $12: 30$ & $13: 30$ & 589 \\
\hline 266 & 1703 & 1814 & 1322 & 742 & 383 & 344 & 518 & 589 \\
\hline \multicolumn{8}{|c|}{ Measured results } \\
\hline 291 & 1593 & 2017 & 1186 & 831 & 417 & 322 & 587 & 569 \\
\hline
\end{tabular}

Table 6. Calculated and measured results for second half of the weekdays

\begin{tabular}{|c|c|c|c|c|c|c|}
\hline \multicolumn{7}{|c|}{ Calculated results } \\
\hline $14: 30-$ & $15: 30-$ & $16: 30-$ & $17: 30-$ & $18: 30-$ & $19: 30-$ & $20: 30-$ \\
$15: 30$ & $16: 30$ & $17: 30$ & $18: 30$ & $19: 30$ & $20: 30$ & $21: 30$ \\
\hline 702 & 1315 & 1120 & 673 & 306 & 135 & 54 \\
\hline \multicolumn{7}{|c|}{ Measured results } \\
\hline 679 & 1425 & 997 & 765 & 273 & 132 & 60 \\
\hline
\end{tabular}

Table 7. Calculated and measured results for the first two thirds of weekends

\begin{tabular}{|c|c|c|c|c|c|c|c|c|c|c|c|}
\hline \multicolumn{10}{|c|}{ Calculated results } \\
\hline $5: 30-$ & $6: 30-$ & $7: 30-$ & $8: 30-$ & $9: 30-$ & $10: 30-$ & $11: 30-$ & $12: 30-$ & $13: 30-$ & $14: 30-$ & $15: 30-$ & $16: 30-$ \\
$6: 30$ & $7: 30$ & $8: 30$ & $9: 30$ & $10: 30$ & $11: 30$ & $12: 30$ & $13: 30$ & $14: 30$ & $15: 30$ & $16: 30$ & $17: 30$ \\
\hline 34 & 122 & 260 & 341 & 361 & 310 & 220 & 256 & 183 & 186 & 230 & 189 \\
\hline \multicolumn{10}{|c|}{ Measured results } \\
\hline 35 & 124 & 265 & 348 & 368 & 316 & 224 & 261 & 187 & 190 & 235 & 192 \\
\hline
\end{tabular}

Table 8. Calculated and measured results for the third part of the weekend

\begin{tabular}{|c|c|c|c|}
\hline \multicolumn{5}{|c|}{ Calculated results } \\
\hline $17: 30-18: 30$ & $18: 30-19: 30$ & $19: 30-20: 30$ & $20: 30-21: 30$ \\
\hline 388 & 506 & 458 & 131 \\
\hline \multicolumn{4}{|c|}{ Measured results } \\
\hline 396 & 516 & 467 & 134 \\
\hline
\end{tabular}

Based on these results we calculated the error based on the following formula:

$$
\varepsilon=\left|\frac{f_{\text {mesured }}-f_{\text {calculated }}}{f_{\text {mesured }}}\right| \cdot 100
$$

Table 9. Calculated error for the weekdays

\begin{tabular}{|c|c|c|c|c|c|c|c|}
\hline \multicolumn{7}{|c|}{ Calculated results } \\
\hline $5: 30-$ & $6: 30-$ & $7: 30-$ & $8: 30-$ & $9: 30-$ & $10: 30-$ & $11: 30-$ & $12: 30-$ \\
$6: 30$ & $7: 30$ & $8: 30$ & $9: 30$ & $10: 30$ & $11: 30$ & $12: 30$ & $13: 30$ \\
\hline $8.59 \%$ & $6.91 \%$ & $10.06 \%$ & $11.47 \%$ & $10.71 \%$ & $8.15 \%$ & $6.83 \%$ & $11.75 \%$ \\
\hline $13: 30-$ & $14: 30-$ & $15: 30-$ & $16: 30-$ & $17: 30-$ & $18: 30-$ & $19: 30-$ & $20: 30-$ \\
$14: 30$ & $15: 30$ & $16: 30$ & $17: 30$ & $18: 30$ & $19: 30$ & $20: 30$ & $21: 30$ \\
\hline $3.51 \%$ & $3.39 \%$ & $7.72 \%$ & $12.34 \%$ & $12.03 \%$ & $12.09 \%$ & $2.27 \%$ & $10.00 \%$ \\
\hline
\end{tabular}

Table 10. Calculated error for the weekends

\begin{tabular}{|c|c|c|c|c|c|c|c|}
\hline $\begin{array}{c}5: 30- \\
6: 30 \\
\end{array}$ & $\begin{array}{c}6: 30- \\
7: 30\end{array}$ & $\begin{array}{l}7: 30- \\
8: 30 \\
\end{array}$ & $\begin{array}{l}8: 30- \\
9: 30 \\
\end{array}$ & $\begin{array}{l}9: 30- \\
10: 30\end{array}$ & $\begin{array}{c}10: 30- \\
11: 30\end{array}$ & $\begin{array}{c}11: 30- \\
12: 30\end{array}$ & $\begin{array}{c}12: 30- \\
13: 30\end{array}$ \\
\hline $2.86 \%$ & $1.61 \%$ & $1.89 \%$ & $2.01 \%$ & $1.90 \%$ & $1.90 \%$ & $1.79 \%$ & $1.92 \%$ \\
\hline $\begin{array}{c}13: 30- \\
14: 30\end{array}$ & $\begin{array}{c}14: 30- \\
15: 30\end{array}$ & $\begin{array}{c}15: 30- \\
16: 30\end{array}$ & $\begin{array}{c}16: 30- \\
17: 30\end{array}$ & $\begin{array}{c}17: 30- \\
18: 30\end{array}$ & $\begin{array}{c}18: 30- \\
19: 30\end{array}$ & $\begin{array}{c}19: 30- \\
20: 30\end{array}$ & $\begin{array}{c}20: 30- \\
21: 30\end{array}$ \\
\hline $2.14 \%$ & $2.11 \%$ & $2.13 \%$ & $1.56 \%$ & $2.02 \%$ & $1.94 \%$ & $1.93 \%$ & $2.24 \%$ \\
\hline
\end{tabular}


The error is within the limit and all the graphic for the passenger trips for one week can be seen in the figure bellow.

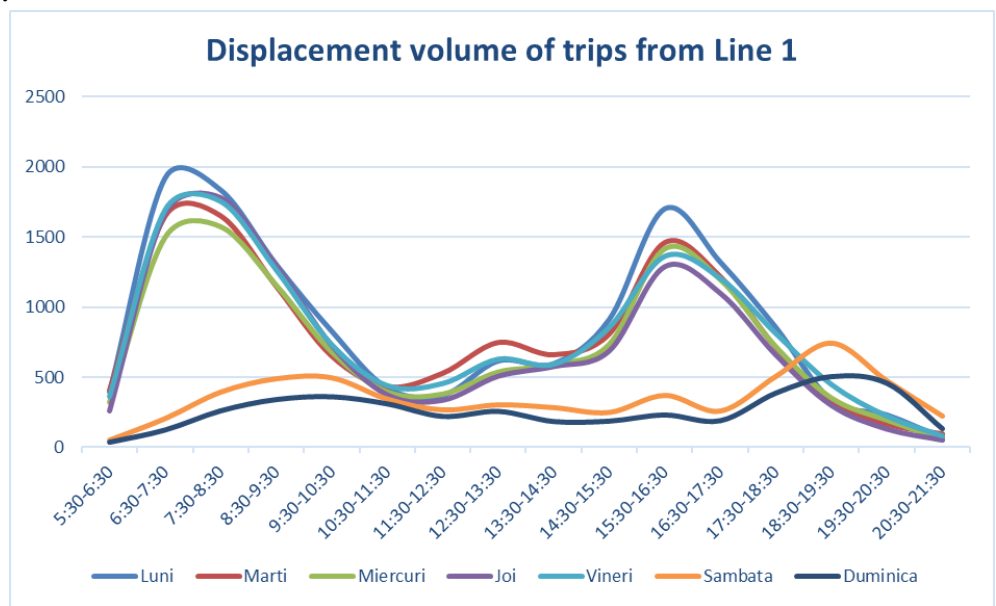

Figure 6. Displacement volume of trips for line 1 on one week

\section{Conclusion}

Based on the results of the polynomial calculation and the errors, that is within the $15 \%$, we draw the following conclusions:

- We used for the approximation of the functions, equations we used to calculate the passenger trips, different numerical methods;

- The purpose behind these equations is to reduce the time spend on the field to measure and gather information's;

- Another way to look at the time saving purpose is that it will enable a reduction in cost, human resource, materials, consumable, etc.

- The errors are within decent limits with small rises on different time interval.

\section{References}

[1] Dumitru, I. Dumitru, N. Matei, L. Racila L. 2016 Public transport traffic management systems simulation in Craiova city, XII Conference on Transport Engineering 7-9, Valencia (Spain)

[2] S. Ilgin Guler, Monica Menendez 2015, Pre-signals for bus priority: basic guidelines for implementation, Public Transport, Volume 7, Issue 3, Springer

[3] Marie Schmidt, Stefan Voß 2017, Advanced systems in public transport, Public Transport, Volume 9, Issue 1-2, Springer

[4] McNally, M. 2000 The Four-Step Model, Handbook of transport modelling, vol. 1

[5] Blum, J. and Edsell, S. 2011 Selective Solution Pool Pruning in Multi-agent Optimization Systems for the Transit Route Network Design Problem

[6] Matei, L., Dumitru I., Racilă L. 2016 Mathematical algorithm total traffic lights cycle calculation in junctions, CONAT 2016

[7] Andrei D. Polyanin, Alexander V. Manzhirov 2007 Handbook of mathematics for engineers and scientists Chapman \& Hall/CRC, Taylor \& Francis ISBN 1-58488-502-5

[8] R. Militaru, A. Calin, G. Calugaru, A. Georgescu 2011 Pachet utilitar de calcul numeric - Numerical Engineering Software Ed. Sitech ISBN 978-606-11-1544-0

[9] V Oţăt, D Bolcu, WW Thierheimer, L Simniceanu 2005 Vehicle Dynamics University Publishing

[10] Constantinescu, A., Trotea, M., Simniceanu, L., Ilie, S. 2001 Mobility study to increase the efficiency of the transport of persons in Dolj county, CAR2011 International Automotive Congress, Automotive Engineering and Environment

[11] Marco Batarce, Juan Carlos Muñoz, and Juan de Dios Ortúzar 2016 Valuing Crowding in Public Transport: Implications for Cost-benefit Analysis Transportation Research A, Vol. 91

[12] Kittleson \& Associates 2013 Transit Capacity and Quality of Service Manual - Third Edition, TCRP Web Document Transit Cooperative Research Program 